\title{
Research on Market-Oriented Selection and Exit Strategy of Professional Managers of State-owned Group Enterprises
}

\begin{abstract}
Zhao Jian ${ }^{1, \mathrm{a}^{*}}$, Zhang Hualei ${ }^{2, \mathrm{~b}}$
State Grid Energy Research Institute Co., Ltd., Beijing, China

$a^{*}$ zhaojian@sgeri.sgcc.com.cn

${ }^{b}$ zhanghualei@sgeri..sgcc.com.cn

ABSTRACT

The purpose of this study is to propose strategies for market-oriented recruitment and exit of professional managers, and to provide strategic references for state-owned group companies to implement the system of professional managers.As the result of the study, the construction of professional managers system in state-owned group enterprises should adopt a bottom-up, pilot first, and steadily promoted approach. In the selection and recruitment mode, professional managers can be introduced for some senior management positions, or professional managers can be introduced for the entire senior management team as a whole.In the selection and recruitment channels, state-owned group enterprises may adopt internal selectionor external selection of professional managers. In the market-oriented exit strategy, state-owned group enterprises may choose internal exit strategy or external exit strategy differently according to the source of professional managers.
\end{abstract}

Keywords: State-owned group enterprises, professional manager, market-oriented recruitment, market-oriented exit

\section{国有集团企业职业经理人市场化选聘及退出策略研究}

\author{
赵简 ${ }^{1, \text { a*张华䂞 }}{ }^{2, b}$
}

网能源研究院有限公司, 北京, 中国

$a^{*}$ zhaojian@sgeri.sgcc.com.cn

${ }^{b}$ zhanghualei@sgeri.sgcc.com.cn

\section{摘要}

本研究的目的是以大型国有企业为研究对象, 研究提出职业经理人市场化选聘及市场化退出的策略, 为国有集团企业推行职业经理人制度提供策略参考。研究认为, 国有集团企业职业经理人制度建设宜 采用自下而上、试点先行、稳妥推进的方式。在选聘模式上，可采用针对部分高管岗位引入职业经理 人, 或针对整个高管团队整体引入职业经理人两种模式。在选聘途径上, 可采用内部选聘职业经理人, 或外部选聘职业经理人两种模式。在市场化退出策略上，可以根据职业经理人来源的不同，差异化选 择内部退出或外部退出的策略。

关键词: 国有集团企业，职业经理人，市场化选聘，市场化退出

\section{1. 前言}

职业经理人是指按照 “市场化选聘、契约化管理、 差异化薪酬、市场化退出”原则选聘和管理的，在充分 授权范围内依靠专业的管理知识、技能和经验, 实现企 业经营目标的高级管理人员。十八届三中全会《中共中
央关于全面深化改革若干重大问题的决定》明确提出, 国有企业要建立职业经理人制度, 合理增加市场化选聘 比例。

2015 年, 国企改革纲领性文件《关于深化国有企业 改革的指导意见》提出 “推行职业经理人制度, 实行内 部培养和外部引进相结合, 畅通现有经营管理者与职业 经理人身份转换通道, 董事会按市场化方式选聘和管理 
职业经理人, 合理增加市场化选聘比例, 加快建立退出 机制” ，职业经理人制度建设成为国有企业改革的重要 抓手。

2016 年, 国资委将 “推进职业经理人制度” 改革定 为十项改革试点之一, 同年, 《关于深化人才发展体制 机制改革的意见》提出要 “研究制定在国有企业建立职 业经理人制度的指导意见” , 中央企业及地方国有企业 开始在下属各级单位开展职业经理人制度的尝试。

2020 年，国务院印发《“双百企业” 推行职业经理 人制度操作指引》, 为国有企业推行职业经理人制度指 明了执行方向。

本研究以大型国有集团企业为研究对象, 总结国有 集团企业市场化选聘、退出职业经理人的典型经验, 提 出国有集团企业职业经理人制度建设的总体思路, 设计 了国有集团企业选聘职业经理人的选聘模式和选聘途 径, 同时结合选聘模式的不同, 提出了职业经理人差异 化的退出策略, 为国有集团企业推行职业经理人制度, 实现市场化选聘和市场化退出提供了策略参考。

\section{2. 国有集团企业职业经理人制度总体思路}

国有集团企业职业经理人制度建设宜采用自下而 上、试点先行、稳妥推进的方式。建立职业经理人制度 是深化国有企业改革的重要方面, 但其实施离不开健全 的公司治理结构与完善的治理机制, 所以国有集团企业 建立职业经理人制度要在全面深化改革的整体框架下 有序实施, 试点先行, 积累经验, 逐步稳妥在集团推进。

具体来看，在集团内部各单位采用自下而上的模式， 针对下属企业外部市场、企业特性、内部管理等因素, 分阶段推进职业经理人制度。先期, 在集团上市公司子 公司层面及非上市公司选取试点单位, 引入职业经理人 制度; 待职业经理人运行机制成熟后, 在集团上市公司 子公司及非上市公司推广, 并在事业部、上市公司逐渐 引入 $[1]$ 。

采用自下而上、试点先行的模式, 其优点在于试错 成本较小, 更容易建立相对灵活的内部机制, 有利于发 现集团企业在推行职业经理人制度中面临的不适应问 题，从而规避全面推进职业经理人制度的潜在风险。

在试点领域选择上, 存量上优先选择处于充分竞争 行业、管理较为规范的企业进行试点, 此类企业的公司 治理结构一般相对完善, 人力资源的市场化程度较高, 企业文化对契约化管理的接受度较好, 具备市场化考核 激励的管理基础, 有利于职业经理人制度的快速推进, 降低试点难度; 增量上, 结合创新跟投、兼并重组民营 企业等混改方式, 借助引资本带动机制转换的有利契机, 探索建立职业经理人制度。

\section{3. 国有集团企业职业经理人选聘模式选择}

国有集团企业引入职业经理人的模式主要分为两
种：一种是针对部分高管岗位引入职业经理人; 另一种 是针对整个高管团队，整体引入职业经理人。国有集团 企业在引入职业经理人时，应根据职业经理人所在岗位 特点、人才招聘难度、企业文化等因素，选择适合的职 业经理人选聘模式 $[2]$ 。

\section{1. 针对部分高管岗位引入职业经理人}

针对部分高管岗位引入职业经理人的方式, 即选择 管理类高管岗位或专业类高管岗位中的部分岗位, 引入 职业经理人的管理方式, 其他高管岗位仍保留原有身份 和管理方式不变。

根据企业当前的经营状况和未来业务拓展需求，职 业经理人一般适用于经营决策层中的两类岗位: 一类是 管理类高管岗位，包括总经理、副总经理等; 另一类是 专业类高管岗位, 包括总会计师、总工程师、总经济师、 总法律顾问等。

针对部分高管岗位引入职业经理人的模式, 其主要 优点在于, 点对点招聘部分具体岗位的职业经理人, 获 取候选人的难度较低, 比较容易招聘到合适的人选。这 种模式的主要劣势在于, 职业经理人与干部身份管理者 在高管层同时存在，容易导致二者之间的公平性问题。 这种问题主要表现为:（1）管理层身份差异导致绩效目 标不一致。对干部身份高管的考核注重 “德能勤绩廉”, 使干部身份高管的管理风格相对稳健, 强调按程序办事、 规避责任; 对职业经理人的考核注重业绩与效率，使职 业经理人的管理风格更为结果导向。管理层内部绩效目 标的不一致, 导致职业经理人的决策受干部身份高管的 掣肘, 束缚职业经理人作用的发挥。(2) 薪酬分配存在 内部公平问题。职业经理人实行市场化薪酬分配机制, 薪酬水平参照市场同行业情况; 干部身份高管薪酬分配 遵循公司内部薪酬制度, 与职业经理人的薪酬差距较大。 薪酬分配的不公平感影响经营层团队凝聚力。

\section{2. 针对整个高管团队, 整体引入职业经理人}

整体引入职业经理人的方式，即针对包括管理类和 专业类在内的整个高管团队，全部采用职业经理人的管 理方式，在高管层不再保留干部身份的管理者。整体引 入职业经理人团队的优点在于, 这种方式解决了职业经 理人与干部身份管理者之间的公平性问题，使整个团队 的工作目标更为一致, 调动了整个高管团队的工作积极 性和主动性, 提升了高管团队的凝聚力。但是这种模式 也存在不足, 由于国内目前职业经理人的人才供给仍然 缺乏，整个高管团队均采用职业经人方式，将大大增加 招聘难度。

\section{4. 国有集团企业职业经理人选聘途径研究}

国有集团企业选聘职业经理人的途径，总体来看可 以分为内部选聘和外部选聘两类。内部选聘, 即候选人 
从南集团内部选拔, 通过身份转换, 聘任为职业经理人; 外部选聘, 即候选人来自集团外部, 通过市场化招聘的 方式聘任为职业经理人。

\section{1. 内部选聘职业经理人}

内部选聘可采用身份转化和系统内招聘两种操作 方式。身份转化, 即将该单位原有干部身份的高管人员 转为职业经理人。系统内招聘, 即面向集团内部, 采用 公开招聘形式, 不拘一格招聘职业经理人。其中, 内部 转身而来的职业经理人, 新签聘用合同, 重新签订劳动 合同。

从适用条件来看, 当企业处于比较稳定市场环境中, 且企业成立时间长、规模较大，内部市场化选人用人管 理机制较为成熟, 内部高级经营管理人才储备充足, 可 以重点考虑在内部培养职业经理人 [3]。

内部选聘职业经理人的主要优点在于, 由于候选人 已经就职于本企业, 使企业能够充分掌握职业经理人能 力、素质、业绩等信息; 职业经理人熟悉本企业情况, 有利于快速适应相关工作; 职业经理人对本企业文化有 较深认识, 减少了因价值观冲突和人际关系冲突, 导致 职业经理人难以融入组织的情况; 内部职业经理人选拔, 为企业内部员工提供了额外的职业发展选择和职业晋 升通道, 能够激励内部用工; 同时, 内部招聘也能够为 企业节约选聘成本。

内部选聘职业经理人的主要劣势在于, 由于职业经 理人岗位数量有限, 招聘选拔过程会带来企业内部的竞 争, 可能会影响员工内部团结; 内部选拔, 可能导致 “近 亲繁殖”、“团体思维”、“裙带关系” 等问题, 影响组织 效能; 可能因企业领导人好恶导致优秀人才埋没, 或因 优秀人才竞争失败而导致人才外流; 内部选聘职业经理 人, 尽快采用了市场化的选聘和人才竞争方式, 但是候 选人仍来自企业内部, 可能造成自我封闭、观念固化、 视野局限, 导致企业缺乏活力与创造力。

\section{2. 外部选聘职业经理人}

外部选聘职业经理人可采用通过混改引入民营企 业职业经理人和外部社会化招聘两种方式。通过混改引 入民营企业职业经理人, 即通过兼并、收购等方式, 在 引入民营资本的同时，引入民营企业职业经理人团队。 外部社会化招聘, 即面向社会公开招聘。

从适用条件来看, 当企业所处市场环境变动剧烈, 且企业必须从旧商业模式向新商业模式转变, 系统内部 缺乏熟悉该领域或业务的高级经营管理人才时, 可以重 点考虑引入外部职业经理人帮助企业实现转型。

外部选聘职业经理人的主要优点在于, 面向市场选 择候选人, 选择范围广, 有利于找到符合需求的人才; 随着外部职业经理人的引入, 可能引入新的价值理念、 管理经验和管理方法, 也可能带来许多新的客户群体, 利于企业开拓创新; 同时, 外部招聘的方式, 可以缓解
内部的竞争矛盾，也会让原有管理者形成危机意识，产 生 “鲶鱼效应”，激发企业内部管理层的潜能和斗志; 可以节省内部培养职业经理人的时间成本和费用支出; 企业可以借助外部选聘的契机进行企业宣传, 提升企业 品牌认知感。

外部选聘职业经理人的主要劣势在于，由于对职业 经理人的素质能力、业绩经历、道德品质等信息掌握不 充分, 与内部选聘相比, 企业对外部候选人的篮选难度 增大、选聘成本提高，甚至会因信息不对称而出现 “逆 向选择”、“道德风险” 等问题; 外部选聘的职业经理人 需要逐渐熟悉国有企业的体制机制、管理风格、人际关 系等, 难以立即开展工作，增加了选人用人的时间成本; 此外，从企业外部空降职业经理人，占用了企业内部员 工原本的职业发展晋升空间, 容易挫伤内部管理者的积 极性和自信心，引发内外部职业经理人的冲突与矛盾。

\section{5. 国有集团企业职业经理人退出策略}

\section{1. 职业经理人退出方式}

从退出的发起方来看, 职业经理人的退出可以分为 主动退出和被动退出。主动退出, 即职业经理人在合同 期满后不再续签合同, 或在合同期未满前主动提出终止 合同的情况; 被动退出, 即因职业经理人绩效不佳、违 法违纪、企业战略调整等原因, 由企业主动提出提前终 止合同或合同期满不再续签合同的要求。

从退出渠道来看, 职业经理人的退出可以分为外部 退出和内部退出。外部退出, 是指职业经理人直接退出 该公司及企业集团; 内部退出，是指不再担任职业经理 人职务, 探索在保留身份的前提下, 降低行政级别, 通 过转任其他职务、调动到集团内部或集团内其他单位、 降职为普通管理/技术人员等方式，继续供职于该公司 或集团。

\section{2. 职业经理人退出方案设计}

职业经理人退出方式的选择应充分考虑选聘方式 的差异, 同时结合职业经理人管理能力、专业特长和本 人意愿, 进行差异化、人性化设计 $[4]$ 。对于不同来源 的职业经理人实行不同的退出方式，集团内选聘的，任 期届满未续聘时可回原单位安排工作，也可结合本人意 愿, 继续留在本单位从事其他岗位工作; 集团外选聘的, 未续聘时依法解除劳动合同。

表 1 不同来源职业经理人退出方式

\begin{tabular}{|l|l|}
\hline 选聘方式 & \multicolumn{1}{|c|}{ 退出方式 } \\
\hline 内部选聘 & $\begin{array}{l}\text { 内部退出, 转任本企业其他工作, 或 } \\
\text { 调动至集团内其他单位。如果愿意继 } \\
\text { 续留在本单位的, 可以采用降职方 }\end{array}$ \\
\hline
\end{tabular}




\begin{tabular}{|l|l|}
\hline & $\begin{array}{l}\text { 式, 允许其从事普通管理/技术人员 } \\
\text { 岗位。 }\end{array}$ \\
\hline 外部选聘 & 解除合同, 外部退出。 \\
\hline
\end{tabular}

\section{6. 职业经理人制度配套保障机制}

加强党组织对职业经理人市场化选聘的领导。建立 健全党委会把关定向、董事会科学决策、职业经理人团 队高效执行、监事会有力监督的决策程序和运行机制, 充分发挥决策班子、经营管理班子、监督班子效用。完 善党委发挥政治核心作用的领导体制。明确党组织在公 司法人治理结构中的法定地位, 在职业经理人市场化选 聘和契约化管理中坚持党的建设同步谋划和开展, 完善 和创新双向进入、交叉任职领导体制, 确保加强党的领 导和完善公司治理相统一的要求在职业经理人制度建 设过程中扎实落地。

优化集团对试点单位的管控模式。根据试点单位企 业股权结构、发展阶段等特点, 分类优化集团对试点单 位的管控模式, 建立健全差异化管控机制。重点在于强 化董事会规范化建设, 差异化落实董事会对高级经营管 理人员选聘、业绩考核和薪酬管理等职权, 健全董事会 内部制衡约束机制; 确保职业经理人团队经营自主权, 差异化设定董事会与经理层的权责界限, 有效保障职业 经理人团队主持公司经营管理工作、落实董事会决议等。

加强企业文化建设, 优化职业经理人制度建设软环 境。淡化行政化倾向和 “家长式” 领导风格, 防止简单 套用党政领导干部管理办法管理职业经理人。营造尊重、 宽容、支持职业经理人的文化环境, 积极引入容错机制, 鼓励职业经理人实施管理创新。坚持市场导向和效率导 向, 有序引导企业文化变革, 提升职业经理人对集团企 业文化环境的适应性。

\section{项目基金}

本文为国家电网公司科技项目《国资国企 改革背景下公司 “做强、做优、做大” 发展理 论与评价体系研究》的阶段性成果之一。

\section{REFERENCES}

[1] Zhang, H.L., Chai, Y., Chen, Q.(2016)Research on the introduction of professional manager system by central enterprises. China Human Resources Development, 20:16-22.

[2] Wang, G.Y. (2019) Difficulties and Reflections on the Implementation of Professional Manager System in State-owned Enterprises. Modern SOE Research, 10:46-47.
[3] Ma, Y. (2019) Thoughts on the introduction of professional manager system in state-owned enterprises. Management Observer, 8:23-27.

[4] Zhou, J. (2019) Three Thoughts on the Construction of Professional Manager System. State-Owned Assets Report,7:26-29. 